\title{
COMPORTAMENTO DA CULTURA DO SORGO EM FUNÇÃO DO TIPO DE RODAS COMPACTADORAS E CARGAS VERTICAIS IMPOSTASS NA OPERAÇÃO DE SEMEADURA
}

\author{
JORGE W. CORTEZ ${ }^{1}$, ALBERTO CARVALHO FILHO ${ }^{2}$, ROUVERSON P. SILVA ${ }^{3}$, \\ CARLOS E. A. FURLANI ${ }^{4}$, DANIEL B. SIMONIS ${ }^{5}$
}

\begin{abstract}
RESUMO: O sorgo pode ser cultivado em áreas e situações ambientais secas e quentes, em que a produtividade de outros cereais é antieconômica. Quando a semeadura do sorgo é realizada de modo eficiente, os benefícios podem ser verificados em sua produtividade. O objetivo deste trabalho foi avaliar o comportamento da cultura do sorgo semeado sob três níveis de carga vertical impostas sobre as rodas compactadoras das semeadoras-adubadoras. $\mathrm{O}$ experimento foi conduzido na FAZU - Faculdades Associadas de Uberaba (MG), no delineamento em blocos ao acaso, no esquema de parcelas subdivididas, com três modelos de rodas compactadoras e três cargas verticais, com cinco repetições. Observou-se que não houve efeito dos tratamentos tipo de rodas compactadoras e cargas em relação aos dias para emergência, mas a regressão linear mostrou significância para carga vertical. A altura, o teor médio de água das plantas e a produção de matéria verde e seca do sorgo não diferiram entre os tratamentos.
\end{abstract}

PALAVRAS-CHAVE: emergência, mecanização agrícola, Sorghum bicolor.

\section{BEHAVIOR OF SORGHUM CROP ACCORDING TO THE PRESS WHELLS TYPE AND VERTICAL LOADS IMPOSED IN THE SOWING OPERATION}

\begin{abstract}
Sorghum can be cultivated in areas and environmental situations droughts and hot, which other cereals productivity is uneconomical. When sorghum sowing is accomplished in an efficient way benefits can be verified in productivity. The objective of this work was to evaluate the behavior of sorghum sowed under three levels of vertical load imposed on the press wheels of the seeder. The experiment was carried out in FAZU - Faculdades Associadas de Uberaba (MG), Brazil, with plots arranged in randomized complete block design in split-plot, with three models of press wheels and three vertical loads with five repetitions. It was observed that there were not effect of the press wheels and loads treatments in relation to the days for emergency, but the lineal regression showed significant for vertical load. The height, the medium moisture of the plants and the production of green and dry matter of the sorghum did not differ among the treatments.
\end{abstract}

KEYWORDS: emergency, mechanization, Sorghum bicolor.

\footnotetext{
${ }^{1}$ Eng ${ }^{\mathrm{o}}$ Agrônomo, Pós-graduando da UNESP - Jaboticabal, Departamento de Engenharia Rural, Fone: (0XX16) 3209-2637, jorge.cortez@posgrad.fcav.unesp.br. Bolsista CAPES.

2 Engo Agrônomo, Prof. Doutor, FAZU - Uberaba e FAFRAM - Ituverava, alberto@ fazu.br

${ }^{3}$ Eng $^{\text {o }}$ Agrícola, Prof. Doutor, Departamento de Engenharia Rural, UNESP - Jaboticabal - SP

${ }^{4}$ Eng $^{\mathrm{O}}$ Agrônomo, Prof. Adjunto, Departamento de Engenharia Rural, UNESP - Jaboticabal - SP

${ }^{5}$ Aluno do curso de Agronomia da FAZU - Faculdades Associadas de Uberaba.

Recebido pelo Conselho Editorial em: 26-10-2005

Aprovado pelo Conselho Editorial em: 4-5-2006
} 


\section{INTRODUÇÃO}

A planta de sorgo (Sorghum bicolor L. Moench) é produto da intervenção do homem que, ao longo de gerações, vem transformando-a para satisfazer as necessidades humanas. Possui enorme potencial em regiões quentes e secas, onde o homem não consegue boas produtividades de grãos ou de forragem cultivando outras espécies, como o milho (RIBAS, 2004).

A recomendação de densidade de sorgo granífero pode variar de 140 a 170 mil plantas por hectare, na colheita. Associado à densidade de semeadura está o espaçamento entre fileiras, que, no Brasil, varia de 0,50 a $0,90 \mathrm{~m}$. Entretanto, verifica-se tendência de utilizar cada vez mais os espaçamentos reduzidos devido ao aumento no rendimento de grãos, por propiciar distribuição melhor de plantas na área, aumentando a eficiência na utilização de luz solar, água e nutrientes, e melhor controle de plantas daninhas, em função do mais rápido fechamento dos espaços disponíveis (VASCONCELOS et al., 2001).

A semeadura de sorgo na entressafra (janeiro a março), no início das chuvas, vem sendo uma opção para a produção de silagem. Utilizando espaçamento de 0,2 a $0,4 \mathrm{~m}$ entre fileiras, são necessários $15 \mathrm{~kg} \mathrm{ha}^{-1}$ de sementes para obter 25 a 40 sementes por metro de sulco, o que revela amplitude para produção de silagem no estande de 2 milhões a 625 mil sementes por ha. A semeadura com máquinas deve ser mais uniforme, devendo a semente estar de 0,03 a 0,04 $\mathrm{m}$ de profundidade e compactadas a fim de proporcionar o melhor contato solo-semente, favorecendo a germinação e o bom enraizamento, o que reflete em maior tolerância a um possível período de estiagem durante o ciclo vegetativo (EVANGELISTA \& LIMA, 2000).

Os fatores que afetam o ambiente radicular para o crescimento das culturas, podem ser a estrutura física, a porosidade e a densidade do solo, que influenciam na capacidade de penetração radicular. Entretanto, quando ocorre compactação adequada pelas rodas compactadoras, as características de permeabilidade, compressibilidade e condução de água e do calor são maximizados (CORTEZ et al., 2004).

O sistema plantio direto acarreta aumento da compactação do solo pela modificação de suas características físicas, decorrentes do tráfego de máquinas, podendo afetar o desenvolvimento de raízes pivotantes e a não-mobilização do solo por meio do tempo (SALLES, 1980).

BAVER (1972), citado por PELLICER (1984), afirma que o aumento da densidade do solo ocorre em função do emprego de forças de compactação e do conteúdo de água, e que a força necessária para compactar o solo decresce exponencialmente com o aumento da umidade. Afirma, também, que os principais impedimentos em solos compactados são as aerações e as impedâncias mecânicas, ou seja, a capacidade de penetração das raízes das plantas é função da porosidade e da compactação do solo.

A operação de semeadura pelas semeadoras-adubadoras aplica ao solo, por meio das rodas compactadoras, certa compactação, que modifica localizadamente o meio ambiente do solo, podendo influenciar no desenvolvimento das plantas (SILVA, 1990). A compactação exercida sobre o solo pelas rodas compactadoras pode ou não ser benéfica à planta e depende, principalmente, da pressão usada sobre a roda e o seu desenho. $\mathrm{O}$ autor sugere que as semeadoras deveriam ser desenvolvidas para aplicar maiores pressões na zona das sementes e colocar solo relativamente solto sobre as mesmas, dependendo do formato da rodas (formato em "V").

Diferentes modelos de roda compactadora apresentam considerável influência sobre o ambiente do solo em torno da semente, dependente do nível de pressão e desenho da roda, do teor de água e do tipo do solo e das condições climáticas no período entre a semeadura (HUMMEL et al., 1981). Assim, a roda compactadora ideal sempre estará por ser comercializada, e geralmente as rodas em forma de $\mathrm{U}$ ou $\mathrm{V}$ fornecem a pressão necessária com um mínimo de peso (RAINBOW, 2000).

SILVA et al. (2005), estudando modelos de rodas compactadoras e cargas verticais na deformação do solo, observaram que as rodas anguladas (pressão lateral), como as convexas largas 
(pressão acima da semente), apresentaram melhores coeficientes de correlação nos diagramas de pressão-deformação.

A germinação das sementes está relacionada ao calor e à umidade, enquanto a emergência das plântulas se relaciona com a profundidade de semeadura e a resistência da camada de solo na linha de semeadura (JUSTINO, 1982). Nesse enfoque, BORTOLI (1985), trabalhando com compactação sobre a semente de $100 ; 200$ e $300 \mathrm{~N}$, promovida pela roda compactadora cilíndrica na cultura do sorgo granífero, verificou que a maior carga favoreceu a emergência para as sementes colocadas a maiores profundidades e prejudicou aquelas semeadas a menores profundidades, concluindo que a melhor compactação para a semente foi de $200 \mathrm{~N}$.

SILVA (1990) cita que a velocidade de emergência e a emergência total de plântulas de feijão decresceram e foram prejudicadas com o aumento da carga de compactação impostas às rodas que efetuaram compactação no solo acima das sementes. O autor ainda cita que os diferentes tipos de roda proporcionaram comportamentos distintos, afetando o ambiente do solo.

A utilização de cargas verticais na operação de semeadura na cultura do sorgo pode alterar o contato solo-semente. Podem, portanto, afetar o crescimento e o desenvolvimento da cultura, pois cargas impostas a diferentes tipos de rodas compactadoras irão pressionar o solo lateralmente ou diretamente sobre a semente, favorecendo ou prejudicando o sistema radicular, cujo efeito será verificado na parte aérea das plantas.

O objetivo deste trabalho foi avaliar o desenvolvimento da cultura do sorgo, em condições de verão no cerrado, semeada com três modelos de rodas compactadoras e três níveis de carga vertical.

\section{MATERIAL E MÉTODOS}

O experimento foi conduzido no ano agrícola 2004-2005, na FAZU - Faculdades Associadas de Uberaba (MG), cujas coordenadas geodésicas são: longitude $47^{\circ} 55$ W', latitude $19^{\circ} 45^{\prime} \mathrm{S}$ e altitude de $780 \mathrm{~m}$. O clima de Uberaba é classificado pelo método de Köeppen como Aw, tropical quente e úmido, com inverno frio e seco, com médias anuais de temperatura e precipitação de $22{ }^{\circ} \mathrm{C}$ e $1.474 \mathrm{~mm}$, respectivamente. O solo da área experimental é um Latossolo Vermelho distrófico, textura média, relevo plano (EMBRAPA, 1999) e densidade média na camada arável igual a $1,5 \mathrm{~g} \mathrm{~cm}^{-3}$.

O experimento foi instalado na Pista de Ensaios de Semeadura da FAZU, desenvolvida por SILVA (2002), que possui sete canais de solo planos, separados por trilhos, que suportam um trole com acionamento elétrico, capaz de realizar atividades de nivelamento, abertura de sulcos para semeadura e carga vertical no solo com rodas compactadoras de diferentes formatos. Os trilhos são espaçados de $2 \mathrm{~m}$ entre si, com comprimento útil de $24 \mathrm{~m}$.

Antes da implantação desse ensaio, a área havia sido utilizada para estudo da crotalária no ano de 2003; logo em seguida, semeou-se na safra de verão 2003-2004 a cultura da soja e na safrinha foi semeada a cultura do milho.

Antes da semeadura, o solo foi irrigado de forma que atingisse a capacidade de campo, e após dois dias esperou-se a drenagem do solo para atingir a friabilidade e realizar a operação da semeadura.

A operação de semeadura foi feita utilizando o sulcador que possuía uma régua graduada acoplada ao trole para abertura dos sulcos na profundidade de $0,04 \mathrm{~m}$; em seguida, foi realizada a deposição da semente no sulco de forma manual, e o recobrimento das sementes foi feito com o solo deslocado pelo sulcador, com o auxílio de uma régua. O sorgo foi semeado em espaçamento reduzido de $0,50 \mathrm{~m}$, proporcionando densidade de 800 mil sementes por ha (40 sementes por metro), de acordo com recomendações de EVANGELISTA \& LIMA (2000), que apresenta amplitude de estande para a cultura do sorgo-silagem de 625 mil a 2 milhões de sementes por ha. Populações menores (140 mil a 170 mil sementes por ha), segundo VASCONCELOS et al. (2001), 
são indicadas para a cultura do sorgo na produção de grãos. A adubação foi com a fórmula 2-26-18, dose de $230 \mathrm{~kg} \mathrm{ha}^{-1}$, e a distribuição do nitrogênio em cobertura foi na dose de $80 \mathrm{~kg} \mathrm{ha}^{-1}$.

Cada parcela do experimento possuía $7,3 \mathrm{~m}$ por $2 \mathrm{~m}\left(14,6 \mathrm{~m}^{2}\right)$, sendo os tratamentos montados no delineamento em blocos ao acaso, no esquema de parcelas subdivididas 3 x 3 (Figura 1), com três modelos de rodas compactadoras e três níveis de carga vertical, com cinco repetições. As rodas avaliadas, apresentadas na Figura 2, foram: em ' $V$ simples' (R1), roda dupla angulada, constituída por duas rodas cilíndricas em $\mathrm{V}$, revestidas por borracha maciça, normalmente usada para plantio direto; roda dupla em 'V com nervura simples' (R2), constituídas por duas rodas cilíndricas, revestidas com borracha maciça e nervura central, por possuir eixo inclinado, essa roda acompanha a forma de um $\mathrm{V}$, e uma roda lisa (R3), convexa larga, sendo revestida com borracha deformável tipo câmara de ar (SILVA, 1990).

\begin{tabular}{|c|c|c|c|c|} 
Pista 1 & Pista 2 & Pista 3 & Pista 4 & Pista 5 \\
\hline $\begin{array}{c}\text { R1-R2-R3 } \\
\text { C3 }\end{array}$ & R2-R1-R3 & R1-R3-R2 & R3-R2-R1 & R3-R1-R2 \\
C2 & C1 & C2 & C1 \\
\hline \multicolumn{5}{|c|}{ Intervalo } \\
\hline R1-R2-R3 & R2-R1-R3 & R1-R3-R2 & R3-R2-R1 & R3-R1-R2 \\
C2 & C3 & C3 & C1 & C2 \\
\hline \multicolumn{5}{|c|}{ Intervalo } \\
\hline R1-R2-R3 & R2-R1-R3 & R1-R3-R2 & R3-R2-R1 & R3-R1-R2 \\
C1 & C1 & C2 & C3 & C3 \\
\hline
\end{tabular}

FIGURA 1. Esquema da área com os tratamentos utilizados $(\mathrm{R}=$ modelo de roda; $\mathrm{C}=$ carga vertical).

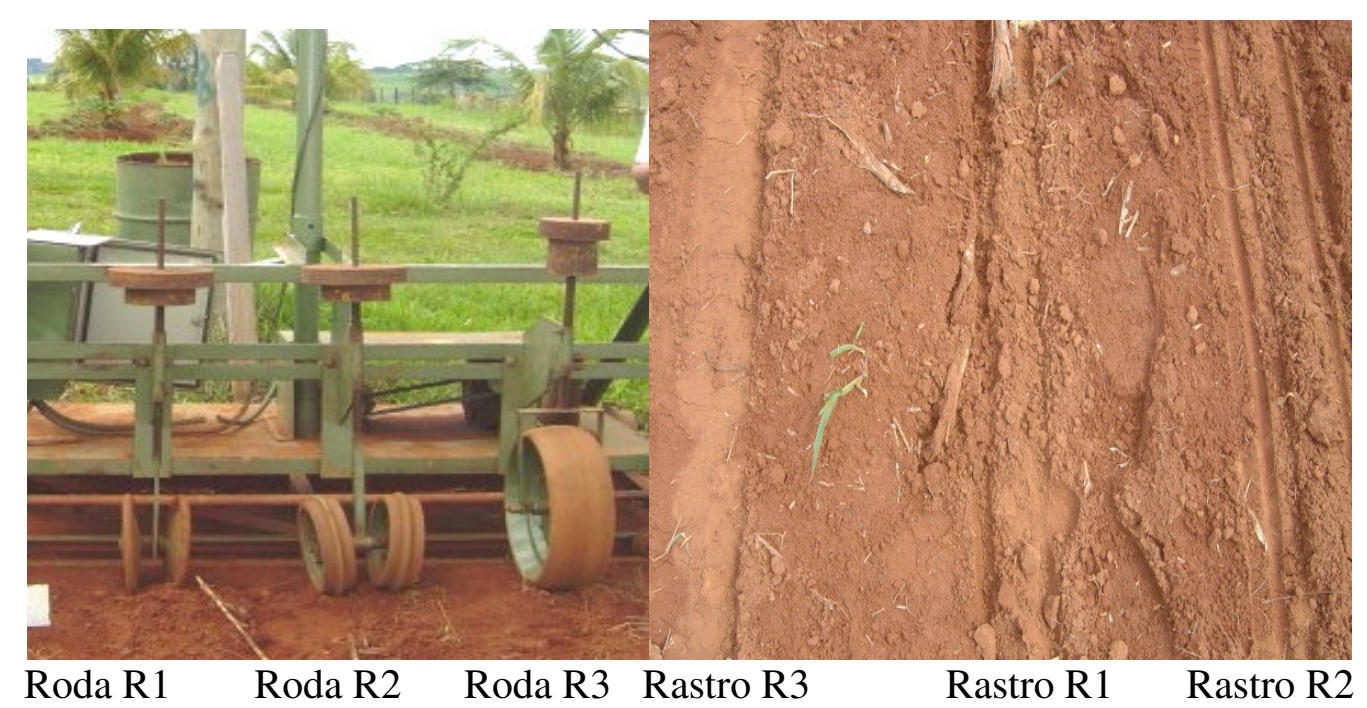

FIGURA 2. Modelos de rodas (R1, R2 e R3) e resultado do trabalho da compactação na linha de semeadura no solo (R3, R1 e R2).

As cargas verticais utilizadas sobre as rodas compactadoras foram: $\mathrm{C} 1(0 \mathrm{~N}), \mathrm{C} 2(100 \mathrm{~N}) \mathrm{e}$ C3 $(200 \mathrm{~N}$ ) inseridas nas rodas por meio de massas cilíndricas devidamente mensuradas (Figura 1) e adaptadas à roda por um furo central, colocando-a sobre seu eixo.

Foram coletados dados de emergência das plântulas até o décimo dia após a semeadura, quando ocorreu a estabilização do número de plântulas emergidas. O número médio de dias para a emergência foi determinado por meio da equação de EDMOND \& DRAPALA (1958), citados por SIQUEIRA (1999). 


$$
M=\frac{\left[\left(N_{1} G_{1}\right)+\left(N_{2} G_{2}\right)+\ldots+\left(N_{n} G_{n}\right)\right]}{\left(G_{1}+G_{2}+\cdots+G_{n}\right)}
$$

em que,

M - número médio de dias para a emergência das plântulas;

$\mathrm{N}_{1}$ - número de dias decorridos entre a semeadura e a primeira contagem de plântulas;

$\mathrm{G}_{1}$ - número de plântulas emergidas na primeira contagem;

$\mathrm{N}_{2}$ - número de dias decorridos entre a semeadura e a segunda contagem de plântulas;

$\mathrm{G}_{2}$ - número de plântulas emergidas entre a primeira e a segunda contagem;

$\mathrm{N}_{\mathrm{n}}$ - número de dias decorridos entre a semeadura e a últim a contagem de plântulas, e

$\mathrm{G}_{\mathrm{n}}$ - número de plântulas emergidas entre a penúltima e a última contagem.

Também foi realizada, na época de colheita para silagem, a coleta de cinco plantas por parcela na linha central para a determinação da massa de matéria verde e, após secagem em estufa de 105 a $110{ }^{\circ} \mathrm{C}$ (EMBRAPA, 1997), a massa de matéria seca e o teor médio de água (TMA) das plantas. Os dados foram tabulados e submetidos à análise de variância e, quando houve significância, ao teste $\mathrm{F}$, a $5 \%$ de probabilidade, foram submetidos ao teste de Tukey para comparação das médias. Quando a interação foi significativa, fez-se o desdobramento das médias, e quando não ocorreu significância pelo teste $\mathrm{F}$, desdobrou-se a regressão pelo método Ortogonal para analisar a ocorrência de correlação.

\section{RESULTADOS E DISCUSSÃO}

O resultado da análise de número de dias para emergência (NDE), pelo teste $\mathrm{F}$, a $5 \%$, não foi significativo para carga $(C)$ e para a interação carga $x$ rodas $(C \times R)$, o que pode ser explicado pelo alto teor de água do solo proporcionado pela irrigação diária antes da semeadura. Para os tipos de rodas compactadoras $(\mathrm{R})$, ocorreu diferença pelo teste $\mathrm{F}$, a $5 \%$ de probabilidade (Tabela 1), enquanto, ao ser analisado pelo teste de Tukey (Tabela 2), não se observa diferença entre as médias; isso é explicado porque, na realização do teste de Tukey, indica que poderá haver diferença significativa em $95 \%$ dos casos, mas que existe $5 \%$ de probabilidade de não ser significativo, como ocorreu neste experimento.

TABELA 1. Resultado da análise de variância para número de dias para emergência (NDE).

\begin{tabular}{lcccc}
\hline Causas de Variação & Graus de Liberdade Soma de Quadrados & Quadrado Médio & F Calculado \\
\hline Blocos & 4 & 0,12 & 0,30 & $0,80 \mathrm{NS}$ \\
Cargas (C) & 2 & 0,05 & 0,03 & $0,71 \mathrm{NS}$ \\
Resíduo A & 8 & 0,30 & 0,04 & \\
\hline Parcelas & 14 & 0,48 & & $3,49 *$ \\
\hline Rodas (R) & 2 & 0,02 & 0,07 & $0,49 \mathrm{NS}$ \\
Interação C x R & 4 & 0,04 & 0,01 & \\
Resíduo B & 24 & 0,51 & 0,02 & \\
\hline Total & 44 & 1,19 & &
\end{tabular}

*Significativo a 5\% de probabilidade pelo teste F; NS não-significativo pelo teste F, a 5\% de probabilidade.

Em experimento realizado por SILVA (2002), as rodas compactadoras não diferiram entre si para o processo de emergência da cultura do milho, mas à medida que aumentaram as cargas verticais sobre elas, diminuiu o número de dias para emergência, o que não foi verificado neste experimento.

Contrariando os resultados obtidos neste experimento, PRADO et al. (2002) observaram que o trabalho da roda compactadora com $150 \mathrm{~N}$ de carga vertical proporcionou maior vigor da plântula e a velocidade de emergência, pois, segundo os autores, em solos sem pressão (carga $0 \mathrm{~N}$ ), ocorre menor taxa de transmissão de água e nutrientes por meio da interface solo/semente/raiz e que uma pequena compactação sobre a semente apresenta um leve benefício. 
Na Figura 3, observa-se que a regressão linear foi significativa para cargas verticais $\left(\mathrm{R}^{2}=\right.$ 0,98 ), onde, à medida que se aumentou a carga vertical, houve aumento no número de dias necessário para a emergência do sorgo. Em termos práticos, não se observa diferença entre 5,16 dias para 5,28 dias, quanto observado em uma escala de 0 a 5,28 dias.

Este resultado discorda de SILVA (2002), que analisou a emergência do milho em profundidades de semeadura para rodas compactadoras e cargas verticais que não alteraram o número de dias para emergência. Nesse contexto, SILVA (1990) conclui que, antes da emergência, a compactação mostrou-se desfavorável ao desenvolvimento da plântula e, após a emergência, foi favorável ao desenvolvimento da mesma pela melhoria do ambiente radicular.

TABELA 2. Síntese do teste de médias para número de dias para emergência (NDE), altura de plantas $(\mathrm{cm})$ aos 30 DAS e na época de colheita para silagem da cultura do sorgo (Ponto de Silagem).

\begin{tabular}{|c|c|c|c|}
\hline Tratamento & \multirow{2}{*}{ NDE } & \multicolumn{2}{|c|}{ Altura de plantas $(\mathrm{cm})$} \\
\hline Cargas (C) & & $30 \mathrm{DAS}$ & Ponto de Silagem \\
\hline $\mathrm{C} 1$ & $5,18 \mathrm{a}^{*}$ & $31,1 \mathrm{a}^{*}$ & $224,3 \mathrm{a}$ \\
\hline $\mathrm{C} 2$ & $5,20 \mathrm{a}$ & $30,9 \mathrm{a}$ & $222,0 \mathrm{a}$ \\
\hline $\mathrm{C} 3$ & $5,26 \mathrm{a}$ & $34,2 \mathrm{a}$ & $222,0 \mathrm{a}$ \\
\hline$\overline{\mathrm{DMS}}$ & 0,20 & 4,8 & 13,2 \\
\hline C.V. (\%) & 3,75 & 14,9 & 5,7 \\
\hline \multicolumn{4}{|l|}{ Rodas (R) } \\
\hline $\mathrm{R} 1$ & $5,30 \mathrm{a}$ & $31,9 \mathrm{a}$ & $224,4 \mathrm{a}$ \\
\hline $\mathrm{R} 2$ & $5,18 \mathrm{a}$ & $31,2 \mathrm{a}$ & $221,3 \mathrm{a}$ \\
\hline R3 & $5,17 \mathrm{a}$ & $33,1 \mathrm{a}$ & $224,4 \mathrm{a}$ \\
\hline DMS & 0,13 & 3,3 & 4,6 \\
\hline C.V. $(\%)$ & 2,82 & 11,4 & 2,2 \\
\hline
\end{tabular}

*Médias seguidas de mesma letra na coluna não diferem entre si, pelo teste de Tukey, a 5\% de probabilidade.

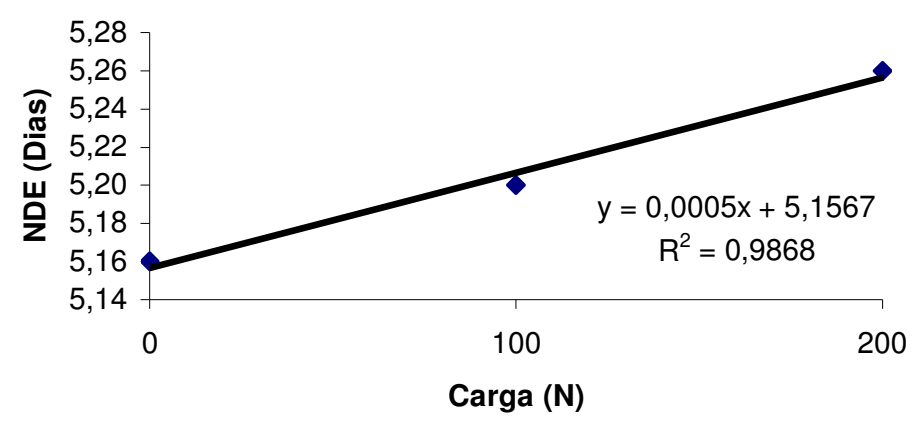

FIGURA 3. Regressão linear entre cargas verticais para número de dias para emergência.

$\mathrm{Na}$ Tabela 3, são apresentados os valores de altura de plantas obtidos para os tratamentos aos 30 DAS e quando o sorgo estava em ponto de corte para silagem (Ponto de Silagem). Os resultados para 30 DAS são condizentes com BORTOLI (1985) e FERNANDES \& ORTOLANI (1988).

Observa-se que a cultura do sorgo não apresentou diferença de altura porque, segundo ROSOLEM (1995) e SILVA (2002), em ambiente propício, as plantas tendem a se igualar em altura, pois a conformação final da planta é genética. As rodas compactadoras (tipo e carga) não proporcionaram diferença significativa na altura, aos 30 dias, resultado semelhante ao encontrado por SILVA (1990) e SILVA (2002) entre as mesmas rodas, em épocas distintas de avaliação para as culturas do feijão e do milho, respectivamente. No final do ciclo, a altura da planta do sorgo não foi influenciada nos tratamentos principais, mas a interação cargas e rodas foi significativa. A 
diferença significativa ocorreu dentro do desdobramento da interação rodas dentro da C2, conforme apresentado na Tabela 3.

TABELA 3. Interação rodas dentro da C2 para altura de plantas no final do ciclo.

\begin{tabular}{cc}
\hline Rodas & Altura $(\mathrm{cm})$ \\
\hline R1 & $226,12 \mathrm{a}^{*}$ \\
R2 & $217,96 \mathrm{~b}$ \\
R3 & $222,08 \mathrm{ab}$ \\
\hline
\end{tabular}

*Médias seguidas de mesma letra na coluna não diferem entre si, pelo teste de Tukey, a 5\% de probabilidade.

A roda compactadora $\mathrm{R} 1$, por não apresentar compactação direta sobre a semente, provavelmente, ocasionou melhor desenvolvimento da planta de sorgo, fazendo com que ela chegasse a maior desenvolvimento ao final do ciclo. Segundo RIBEIRO (1998), a compactação excessiva causa efeitos nocivos e, a fim de evitar esses efeitos, podem ser usadas as rodas compactadoras em $\mathrm{V}$, pois quanto maior o ângulo de abertura, a quantidade de solo lançado sobre a semente aumenta e pelo alívio central com maior compactação lateral obtém-se melhor contato solo-semente.

PELLICER (1984) observou que cargas verticais pesadas (300 N) provocaram menor altura de plantas, diferindo das demais cargas estudadas. JUSTINO (1982) observou que a altura das plantas de amendoim diferiu nas compactações 140 e $210 \mathrm{~N}$, independentemente da profundidade de semeadura.

A análise do teor médio de água, da matéria verde e seca não apresentou diferença estatística entre tratamentos, conforme apresentado na Tabela 4.

Pelos resultados, observa-se que as rodas e cargas verticais impostas à semente somente têm influência no processo inicial de semeadura para a emergência, não alterando os resultados de matéria verde e seca. Segundo PELLICER (1984), avaliando a resistência à penetração nas camadas de 0-0,05 e 0,05-0,10 m, essas diferiram das demais, indicando que a compactação sobre a semente não interfere na parte inferior do solo, o que pode ser constatado neste experimento pela igualdade dos dados finais de produção.

ORTOLANI et al. (1986), trabalhando com compactação sobre a semente, concluíram que não basta compactar o solo sobre a semente, sendo necessário saber o quanto compactar, o que é difícil de se determinar em condições de campo.

TABELA 4. Síntese do teste de médias para o teor médio de água, matéria verde e seca.

\begin{tabular}{lccc}
\hline Tratamento & Teor Médio de Água $(\%)$ & Matéria Verde $\left(\mathrm{t} \mathrm{ha}^{-1}\right)$ & Matéria Seca $\left(\mathrm{t} \mathrm{ha}^{-1}\right)$ \\
\hline Cargas $(\mathrm{C})$ & \multicolumn{3}{l}{} \\
\hline C1 & $62,58 \mathrm{a}$ & $69,49 \mathrm{a}^{*}$ & $26,33 \mathrm{a}$ \\
C2 & $59,88 \mathrm{a}$ & $78,11 \mathrm{a}$ & $31,58 \mathrm{a}$ \\
C3 & $62,81 \mathrm{a}$ & $69,90 \mathrm{a}$ & $26,36 \mathrm{a}$ \\
\hline DMS & 6,23 & 24,77 & 12,39 \\
\hline C.V. $(\%)$ & 9,67 & 32,75 & 42,29 \\
\hline Rodas $(\mathrm{R})$ & & & $28,54 \mathrm{a}$ \\
R1 & $61,17 \mathrm{a}$ & $73,22 \mathrm{a}$ & $26,15 \mathrm{a}$ \\
R2 & $62,88 \mathrm{a}$ & $69,88 \mathrm{a}$ & $29,58 \mathrm{a}$ \\
R3 & $61,22 \mathrm{a}$ & $74,41 \mathrm{a}$ & 6,51 \\
\hline DMS & 3,77 & 13,36 & 25,45 \\
C.V. $(\%)$ & 6,70 & 20,23 &
\end{tabular}

*Médias seguidas de mesma letra na coluna não diferem entre si, pelo teste de Tukey, a 5\% de probabilidade. 


\section{CONCLUSÕES}

O número de dias para emergência não foi afetado pelo tipo de roda compactadora e pela carga vertical a ela imposta na semeadura em solo com alta umidade.

A altura de plantas, matéria verde e seca não apresentaram diferenças entre os tratamentos, indicando que, na semeadura de sorgo, as cargas verticais e os tipos de rodas compactadoras não influenciaram no desenvolvimento da cultura.

Para a cultura do sorgo, os tipos de rodas compactadoras não influenciaram no tipo e no condicionamento do solo para a semente e a planta.

\section{REFERÊNCIAS}

BORTOLI, N.M. Influência da profundidade de semeadura e da compactação sobre o solo na faixa de distribuição de sementes, na emergência e desenvolvimento do sorgo granífero (Sorgum bicolor (L.) Moench) híbrido Contrigão-111. 1985. 71 f. Monografia (Trabalho de Graduação em Agronomia) - Faculdade de Ciências Agrárias e Veterinárias, UNESP, Jaboticabal, 1985.

CORTEZ, J.W.; CARVALHO FILHO, A.; SILVA. R.P. Plantadeiras: adensamento. Cultivar Máquinas, Pelotas, n.35, p.14-16, out. 2004.

EMPRESA BRASILEIRA DE PESQUISA AGROPECUÁRIA. Centro Nacional de Pesquisas de Solos. Manual de métodos de análise do solo. Rio de Janeiro, 1997. 212 p.

EMPRESA BRASILEIRA DE PESQUISA AGROPECUÁRIA. Centro Nacional de Pesquisa dos solos. Sistema brasileiro de classificação dos solos. Brasília, 1999. 412 p.

EVANGELISTA, A.R.; LIMA, J.A. de. Silagens: do cultivo ao silo. Lavras: UFLA, 2000. 196 p.

FERNANDES, E.J.; ORTOLANI, A.F. Influência da profundidade de semeadura e compactação do solo sobre a emergência, desenvolvimento e produtividade do sorgo sacarino. In: CONGRESSO BRASILEIRO DE ENGENHARIA AGRÍCOLA, 17., 1988, Iperó. Anais... Iperó: SOCIEDADE BRASILEIRA DE ENGENHARIA AGRÍCOLA, 1988. v.2, p.415-24.

HUMMEL, J.W.; GRAY, L.E.; NAVE, W.R. Soybean emergence from field seedbed environments. Transactions of the ASAE, St Joseph, v.24, n.4, p.872-8, 1981.

JUSTINO, A. Influência da profundidade de semeadura e compactação sobre o solo, na emergência e desenvolvimento inicial do amendoim (Arachis hypogaea L.) variedade TATU. 1982. 91 f. Monografia (Trabalho de Graduação em Agronomia) - Faculdade de Ciências Agrárias e Veterinárias, Universidade Estadual Paulista, Jaboticabal, 1982.

ORTOLANI, A.F.; BANZATTO, D.A.; BORTOLI, N.M. Influência da profundidade de semeadura e da compactação do solo na emergência e desenvolvimento do sorgo granífero (Sorgum bicolor (L.) Moench). In: CONGRESSO BRASILEIRO DE ENGENHARIA AGRÍCOLA, 15., 1986, São Paulo. Anais... São Paulo: SOCIEDADE BRASILEIRA DE ENGENHARIA AGRÍCOLA, 1986. v.2, p.27-39.

PELLICER, C.A.P. Influência da profundidade de semeadura e compactação do solo sobre a semente na emergência, desenvolvimento inicial e produtividade do feijoeiro (Phaseolus vulgaris L.). 1984. 79 f. Monografia (Trabalho de Graduação em Agronomia) - Faculdade de Ciências Agrárias e Veterinárias, Universidade Estadual Paulista, Jaboticabal, 1984.

PRADO, R.M.; NATALE, W.; FURLANI, C.E.A. Manejo mecanizado de atividades para implantação de culturas. Jaboticabal: SBEA, 2002. 99 p. (Série Engenharia Agrícola)

RAINBOW, R. Press wheels and their use in seedling. South Australian Research and Development Institute, Alexandria, 2000. Disponível em:

<http://www.sardi.sa.gov.au/crops/farmsys/f_tillag.htm>. Acesso em: 25 jun. 2000.

RIBAS, P.M. Sistema de produção 2. Sete Lagoas: Embrapa Milho e Sorgo, 2004. "não paginado" 
RIBEIRO, M.F.S. Mecanização agrícola. In: DAROLT, M.R. Plantio Direto: pequena propriedade sustentável. Londrina: IAPAR, 1998. p.95-112.

ROSOLEM, C.A. Relações solo-planta na cultura do milho. Jaboticabal: FUNEP, 1995. 53 p.

SALLES, H.C. Influência da compactação do solo no desenvolvimento da soja (Glycine max (L.) Merril). 1980. 55 f. Monografia (Trabalho de Graduação a Agronomia) - Faculdade de Ciências Agrárias e Veterinárias, Universidade Estadual Paulista, Jaboticabal, 1980.

SILVA, F.M. Influência do tipo de rodas compactadoras de semeadoras-adubadoras, no condicionamento físico do solo e no desenvolvimento de plantas. 1990. $131 \mathrm{f}$. Dissertação (Mestrado em Máquinas Agrícolas) - Faculdade de Engenharia Agrícola, Universidade Estadual de Campinas, Campinas, 1990.

SILVA, R.P.da . Efeito de rodas compactadoras submetidas a cargas verticais em profundidades de semeadura nas características agronômicas do milho (Zea mays L.). 2002. $101 \mathrm{f}$. Tese (Doutorado em Produção Vegetal) - Faculdades de Ciências Agrária e Veterinárias, Universidade Estadual Paulista, Jaboticabal, 2002.

SILVA, R.P.; CORA, J.E.; LOPES, A.; FURLANI, C.E.A. Ação de rodas compactadoras de semeadoras submetidas a cargas verticais na deformação do solo. Ciência e Agrotecnologia, Lavras, v.29, n.4, p.839-47, 2005.

SIQUEIRA, R. Sistemas de preparo em diferentes tipos de coberturas vegetais do solo. 1999. 191 f. Tese (Doutorado em Energia na Agricultura) - Faculdades de Ciências Agronômicas, Universidade Estadual Paulista, Botucatu, 1999.

VASCONCELLOS, C.A.; MARRIEL, I.E.; SANTOS, F.G. dos. Resíduos de sorgo e a mineralização do nitrogênio em Latossolo Vermelho fase cerrado. Scientia Agrícola, Piracicaba, v.58, n.2, p.373-9, abr./jun. 2001. 